\title{
Incidence and mortality of cervical cancer in Latin America
}

Silvina A rrossi, MSC, ${ }^{(1)}$ Rengaswamy Sankaranarayanan, MD, ${ }^{(1)}$ D onald Maxwell Parkin, MD..11

\begin{abstract}
Arrossi S, Sankaranarayanan R, Parkin DM. Incidence and mortality of cervical cancer in Latin America. Salud Publica Mex 2003;45 suppl 3:S306-S314. This paper is available too at: http://www.insp.mx/salud/index.html
\end{abstract}

\begin{abstract}
A bstract
Cervical cancer incidence and mortality estimates for 2000 are presented for the 21 Latin American countries, using estimates from the statistical package GLO BO CAN 2000. Additional data on time-trends are also presented, using the W HO mortality database. By the year 2000, so me 76000 cervical cancer and almost 30000 deaths were estimated for the whole region, which represent $16 \%$ and $13 \%$ of the world burden, respectively. Thus, Latin A merican countries are among those with highest incidence rates in the world, together with countries from Sub-Saharan A frica, South and South East Asia.Variation in incidence among countries is large. Very high rates are found in Haiti (ASR 93.9 per 100000 ), N icaragua (ASR 61.1 per 100000 ) and Bolivia (ASR 58.1 per 100000 ). It seems unlikely that differences in risks in the region can be explained as the result of screening activities. Several descriptive studies carried out to evaluate the screening programmes in Latin A merica have pointed out problems related to insufficient coverage and frequency of screening. 0 ther related problems include inadequate collection and reading of cytological samplings as well as incomplete follow-up of women after the test. The main challenge for Latin A merica countries remains on how to organize effective screening programmes, and for this, a real and urgent commitment from public health
\end{abstract}

Arrossi S, Sankaranarayanan R, Parkin DM. Incidencia y mortalidad de cáncer cervical en A mérica Latina.

Salud Publica Mex 2003;45 supl 3:S306-S314. Este artículo también está disponible en: http://www.insp.mx/salud/index.html

\section{Resumen}

Se presentan estimaciones de la incidencia y de la mortalidad por cáncer cer vical para los 21 países latinoamericanos en el año 2000. Se utilizaron el paquete estadístico GLO BO CAN 2000 y las bases de datos de mortalidad de la $0 \mathrm{r}$ ganización Mundial de la Salud. En el año 2000, al menos 76000 casos incidentes de cáncer cervical y 30000 muertes se estimaron para la Región en general, lo cual representa 16 y 13\% del total del mundo, respectivamente. Por lo tanto, los países de América Latina se encuentran en un área geográfica con tasas de incidencia de las más altas en el mundo, junto con países del Sub-Sahara, en A frica, y del sureste de Asia. La variación de la incidencia entre los países es grande; existen tasas muy altas en Haití (93.9 por 100000 ), $\mathrm{N}$ icaragua (61.1 por 100000 ) y Bolivia (58.1 por 100 000). Es poco probable que las diferencias en los riesgos entre las regiones sean explicadas como resultado de las actividades de tamizaje. Varios estudios descriptivos se han llevado a cabo para evaluar programas de tamizaje en América Latina, señalando problemas relacionados con la frecuencia y la difusión insuficiente del tamizaje. 0 tro problema relacionado incluye la inadecuada colección y lectura de muestras citológicas, así como el seguimiento incompleto de las mujeres después de la prueba. El principal cambio para los países de América Latina se encuentra en

This analysis was supported by a grant from the Bill and Melinda Gates Foundation to the IARC, through the Alliance for Cervical Cancer Prevention (W ebsite: www.alliance-cxca.org).

(1) International A gency for Research on Cancer, Lyon, France.

Received on: 0 ctober 1,2002 - Accepted on: February 17, 2003

Address reprint requests to: Silvina Arrossi, MSC. IARC 150 Cours Albert Thomas 69372, Lyon C edex. France. E-mail: arrossi@iarc.fr 
services and decision-makers in the region is needed.This paper is available too at:http://www.insp.mx/salud/index.html

Key words:cervical cancer; incidence; mortality, public health; Latin America cómo organizar programas efectivos de tamizaje y, para esto, es necesaria una real y urgente integración entre los servicios de salud pública y los tomadores de decisiones en la Región. Este artículo está disponible en:http://ww w.insp.mx/ salud/index.html

Palabras clave: cáncer cervical; incidencia; mortalidad; salud pública;A mérica Latina
L atin America is one of the regions of the world where the incidence of cervical cancer is high. ${ }^{1}$ This tumour is the second most common cancer among women and the second cause of death from cancer. This picture is not new. In 1987, an analysis of trends in cervical cancer in Latin America was published, pointing out not only the magnitude of the problem, but also the fact that, contrary to what was happening in developed countries, mortality due to cervical cancer between 1975 and 1985 had been increasing. ${ }^{2}$ In 1996, a second trend analysis was published, showing that in Latin American countries almost no significant downward changes in mortality had been observed between 1960 and 1993. ${ }^{3}$

The relative lack of success of most Latin American countries in the prevention and control of cervical cancer contrasts with the observation of declines in incidence and mortality in North America. By now, enough evidence exists about the protective effects of well-organized screening programmes, which can potentially reduce incidence and mortality by up to $90 \%{ }^{4}$ This evidence comes mainly from the experience of developed countries, and especially from the Nordic countries $^{5-7}$ where large reductions were achieved following the introduction of population screening programmes. In Latin America, screening programs, where they exist, have been introduced piecemeal, lack both organisation and quality control, and have failed to meet their objectives.

By the year 2000, some 76000 new cervical cancer cases and almost 30000 deaths were estimated for the whole region, which represent $16 \%$ and $13 \%$ of the world burden respectively. This paper examines the geographical variations in incidence and mortality in the 21 Latin American countries (LAC), Argentina, Bolivia, Brazil, Chile, Colombia, Costa Rica, Cuba, Dominican Republic, Ecuador, El Salvador, Guatemala, Haiti, Honduras, Mexico, Nicaragua, Panama, Paraguay, Peru, Puerto Rico, Uruguay and Venezuela. The estimates are taken from GLOBOCAN $2000^{8}$ and have been derived using different sources of information and methods.
Mortality statistics have the great advantage of comprehensive coverage and availability. However, in many Latin American countries coverage is incomplete, while in others, completeness of registration varies according to geographic area and age group. In general, registration of vital events is less complete in rural areas and is worse in areas with poor living conditions. ${ }^{9}$ The proportion of deaths certified as due to ill-defined causes varies from country to country (range 1-48\%) and in general is associated with lack of access to medical services and lack of training or insufficient understanding of the uses of this type of information. Although great improvements have been made in the quality of mortality data during recent years, in some countries, such as Brazil, Honduras, Peru and El Salvador, this continues to be an important problem.

Incidence data are produced by population-based cancer registries (PBCRs), which collect information on all new cases of cancer in a defined population. Cancer registries may cover national populations or, more often, certain cities or regions. ${ }^{1}$ In Latin America, several countries have initiated PBCRs during the last decades (Argentina, Brazil, Chile, Colombia, Costa Rica, Cuba, Paraguay, Peru, Puerto Rico and Uruguay), but in fact most of them have faced difficulties in producing continuous incidence data at a good level of quality. By now, only two registries, in Cali, Colombia, and Puerto Rico, have produced good quality longterm incidence rates. ${ }^{10}$ To overcome these difficulties, estimates of incidence and mortality were produced using all available sources of information, mainly incidence and mortality but also survival data or frequency data where no population-based registry and/or mortality statistics are available.

\section{Material and Methods}

The GLOBOCAN package gives statistical and graphical information on cancer incidence and mortality for 173 countries in the world. The methods used to estimated mortality for the countries of Latin America were as follows: 
1. National mortality data were available for five countries:

Argentina (1998)*

Chile (1995-1998)*

Uruguay (1995-1998)*

Costa Rica $(1993-1995)^{\ddagger}$

Cuba (1993-1996) $)^{\ddagger}$

2. National data were available but known to underestimate the true mortality: The published rates have been corrected by multiplying the estimated percentage of under-registration as published by PAHO. ${ }^{8}$ In the case of Brazil, important differences in the levels of completeness and quality of vital events are observed among sub-regions, and therefore correction was made both for under-registration and for the percentage of ill-defined causes of death using sub-regional proportions as provided by the Brazilian Ministry of Health.

Dominican Republic (1983-1985)

El Salvador (1991-1993)

Mexico $(1993-1995)^{\ddagger}$

Panama (1989)

Colombia (1992-1994

Ecuador $(1993-1995)^{\ddagger}$

Venezuela $(1992-1994)^{\ddagger}$

Brazil (1995-1998)*

3. Estimates were derived from data of one or more cancer registries covering the whole country: Puerto Rico (1991).

4. Mortality was estimated from incidence, using country/regional survival when no recent cancer mortality data were available or known to be of poor quality:

Haiti, Guatemala, Honduras, Nicaragua, Bolivia, Paraguay and Peru.

Within LAC many deaths from cancer of the uterine cervix and uterine corpus are inadequately coded as "uterine cancer not otherwise specified" (ICD-9 179). This lack of specificity in the assignment of uterine cancer deaths was corrected by allocating the deaths coded as "unspecified" to either uterine cervix (ICD-9 180 ) or uterine corpus cancer (ICD-9 182) according to the age-specific proportions specified as 180 and 182 in each country. Thus, mortality estimates may not correspond to the rate published by WHO. ${ }^{11}$ This correc-

\footnotetext{
* Data provided by national Ministries of Health.

$\ddagger$ Data provided by WHO.
}

tion was applied also to incidence data from cancer registries, although the proportion of "unspecified" cases is much smaller than in mortality data.

\section{Incidence}

In countries with good national cancer registration systems, this was the preferred source of incidence data. For all other countries, incidence was estimated from mortality by assuming that the logarithm of the incidence rate of a given cancer can be expressed as a linear function of the logarithm of mortality in each sexage group. ${ }^{12}$ The ratio of mortality to incidence $(\mathrm{M} / \mathrm{I})$ is a good indicator of the completeness of cancer registry data. ${ }^{13}$ To ensure that these datasets were the highest possible quality, careful consideration of each registry* sex specific $\mathrm{M} / \mathrm{I}$ ratios for each primary site was made. Registries were excluded from the model datasets if the $\mathrm{M} / \mathrm{I}$ ratios were considered unreasonably high or low for the cancer in question. Thus, the specific model for countries from LAC was built based on available mortality and incidence data provided by five Latin American cancer registries: Montevideo, Uruguay (19901992), Puerto Rico (1988-1991), Cali, Colombia (19871991), Cuba (1986) and Costa Rica (1988-1992).

1. Good quality incidence data at national level was available for: Costa Rica (CI5-VII, 1988-1992) and Puerto Rico (CI5-VII, 1988-1991).

2. Incidence estimates were based on mortality data using the "LAC" model:

Argentina, Chile, Uruguay, Venezuela, Brazil, Dominican Republic, El Salvador, Panama, Colombia and Ecuador (corrections made for countries with low quality data as explained in the mortality section).

3. Incidence data from cancer registries with local/ regional coverage were taken as representative of the country:

Paraguay: Asuncion, 1988-1989.

Peru: Trujillo, 1991-1995 and Lima, 1990-1991.

4. When the quality of the mortality data was very low (under-registration over $40 \%$ ) and no incidence data were available, an average sub-regional rate for all sites was built based on incidence data from countries in the sub-region for which meth-

\footnotetext{
* Only Latin American registries with published data in CI5-VI or VII were considered.
} 
ods 1, 2 or 3 were used. For each specific country, this average rate was partitioned using any available data on the relative frequency of different cancers (by age and sex) taken from scientific articles or existing mortality data. The sets of "all sites" incidence rates were built as follows:

The Caribbean: incidence rates from Cuba, Dominican Republic, Jamaica, Puerto Rico and Trinidad and Tobago; Central America: incidence rates from Costa Rica, El Salvador, Mexico and Panama; South America: incidence rates from Brazil, Colombia, Ecuador, Guyana, Suriname and Venezuela.

Nicaragua: set of regional rates + proportions (WHO mortality (1992-1994) converted to incidence.

Haiti: set of regional rates + proportions. ${ }^{14}$

Bolivia: set of regional rates + proportions, La Paz (1988-1992).

5. No data: The country-specific rates are calculated from the average of the estimated rates for countries in the same country sub-region for which methods 1, 2 or 3 were used:

Guatemala and Honduras: average of incidence rates of Costa Rica, El Salvador, Mexico and Panama.

Incidence and mortality rates are presented as Age Standardized Rates, calculated using the weights of the "world standard" population in five age classes: $0-15,15-44,45-54,55-64$ and 65 years and older (0.31, $0.43,0.11,0.08$ and 0.07$)$. Estimates of country populations (by age and sex) for the year 2000 were taken from the United Nations population projections. ${ }^{15}$

\section{Incidence and mortality data in time trend analysis}

Difficulties in using incidence and mortality data for the analysis of cervical cancer time trends have been widely recognized. ${ }^{1,16}$ It frequently happens that socio-economic development is accompanied both by changes in the quality of available data (especially mortality) and in the risk of cervix cancer. The same applies to the problems linked to the capacity to distinguish cancers of the cervix and corpus, as already mentioned. This complicates interpretation of trends based on published data. Despite these difficulties, the work carried out by Restrepo and colleagues ${ }^{2}$ and Robles and colleagues $^{3}$ showed that much can be learnt about the evolution of cervical cancer in Latin America using available data. As in these previous studies, data has been taken from the WHO database ${ }^{11}$ and no correction was performed for deaths coded as "uterus unspeci- fied". Thus, mortality rates used in time trend analysis may differ from data from GLOBOCAN 2000 presented above. Countries have been selected according to two criteria: a low level of under-registration (up to $25 \%$ ) and the availability of reasonably long time series in the WHO database. The years for which data are available vary from country to country and therefore time series do not always coincide.

\section{Results}

Figure 1 shows the world geographical distribution of cervical cancer age standardized incidence rates by country. Two facts are evident from this map: The first one is that in the year 2000 most Latin countries were among those with incidence rates in the highest two quintiles, together with countries from Sub-Saharan Africa, South and South East Asia. The exceptions are Argentina (ASR 14.2 per 100 000), Uruguay (ASR 13.8 per 100 000) and Puerto Rico (ASR 10.3 per 100 000), with rates similar to the level observed in Western Europe. ${ }^{17}$ The second observation is the large variation found between countries (see also Figures 2 and 3 ). The Latin Caribbean has the lowest and the highest risks in the whole of Latin America, Puerto Rico (ASR 10.3 per 100 000) and Haiti (ASR 93.9 per 100 000). The estimated incidence for Haiti is the highest in the world; this is because incidence was estimated using the only available data on frequency of different cancers in the country. In effect, in the special survey of cancer cases carried out by Mitacek, ${ }^{14}$ cervical cancer represented around $40 \%$ of total female cancer cases. Very high rates are also found in Nicaragua (ASR 61.1 per 100000 ) and Bolivia (ASR 58.1 per 100 000), in South and Central America respectively. Total estimated new cases and deaths from cervical cancer in each country are presented in Table I.

The ratio of mortality to incidence is around $40 \%$, although Haiti, Uruguay, Argentina and Costa Rica have $\mathrm{M} / \mathrm{I}$ ratios of $45 \%$ or higher.

\section{Determinants of variations in risks}

Variations in incidence among Latin countries are difficult to explain given the lack of data on the geographical distribution of risk factors. Historically, cervical cancer was associated with a number of demographic, cultural and socio-economic variables characteristic of less developed societies (young age at first coitus, elevated number of partners, low socioeconomic status, low education level, poor genital hygiene, among others). Since it has become established that certain sexually transmitted types of human papilloma virus 


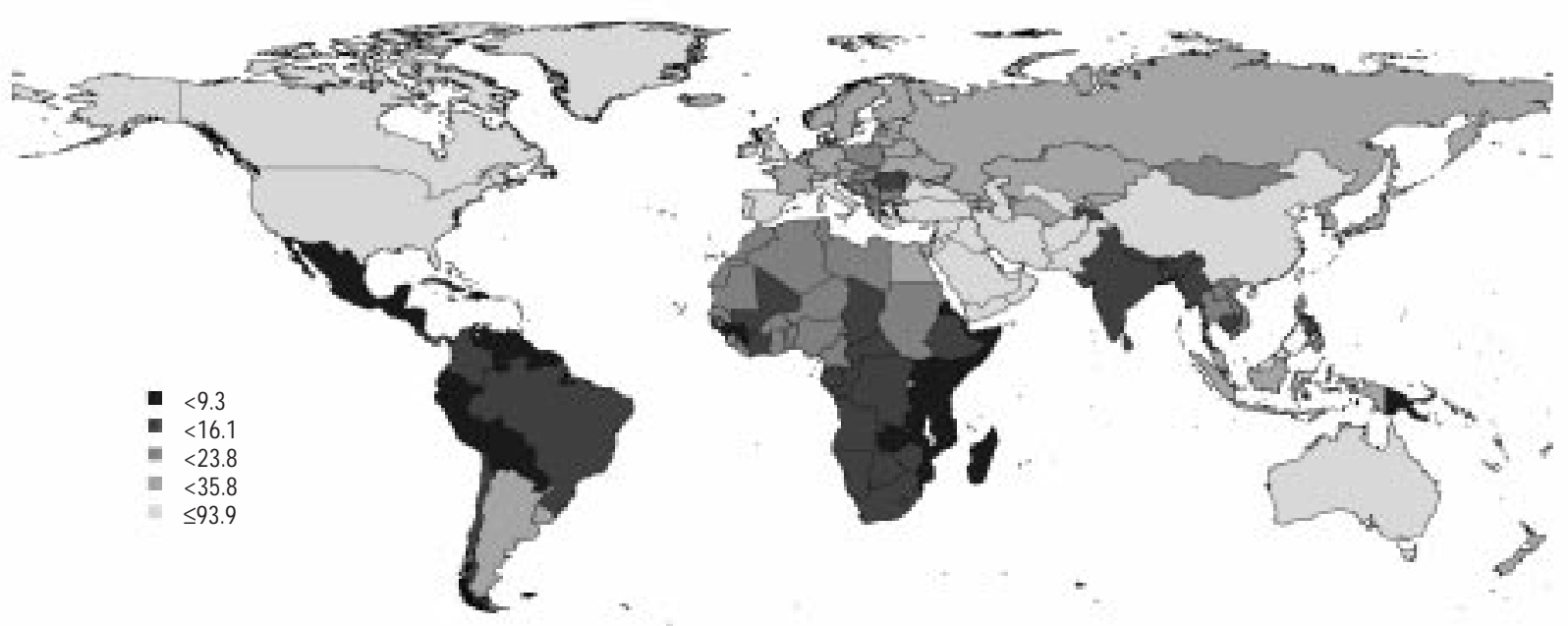

Figure 1. Incidence of Cervix uteri cancer:ASR (World) (All ages)

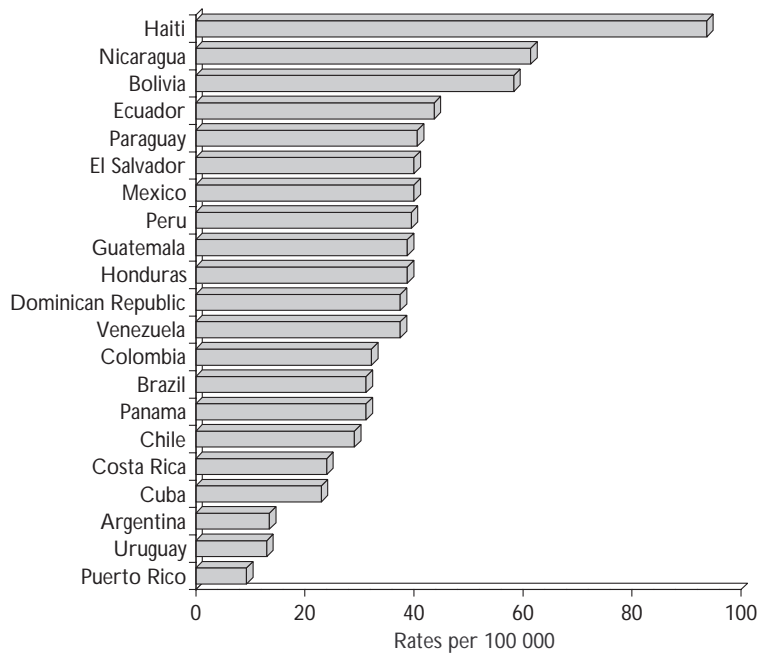

Figure 2. Latin America.Age-Standardized incidence RATE (W ORLD) BY COUNTRIES, 2000

$(\mathrm{HPV})$ are a necessary cause of cervical cancer ${ }^{18}$ it seems that most of these factors are surrogates for HPV infection. However, it is very difficult to establish whether variations in incidence observed among Latin American countries are due to differences in prevalences of HPV infection. Three recent population-based prevalence surveys, carried out in Colombia, Mexico and Costa Rica, gave similar figures of between 15 and $16 \%{ }^{19-21}$ Worldwide, there are very few systematic studies on the prevalence of HPV infection, but in ge-

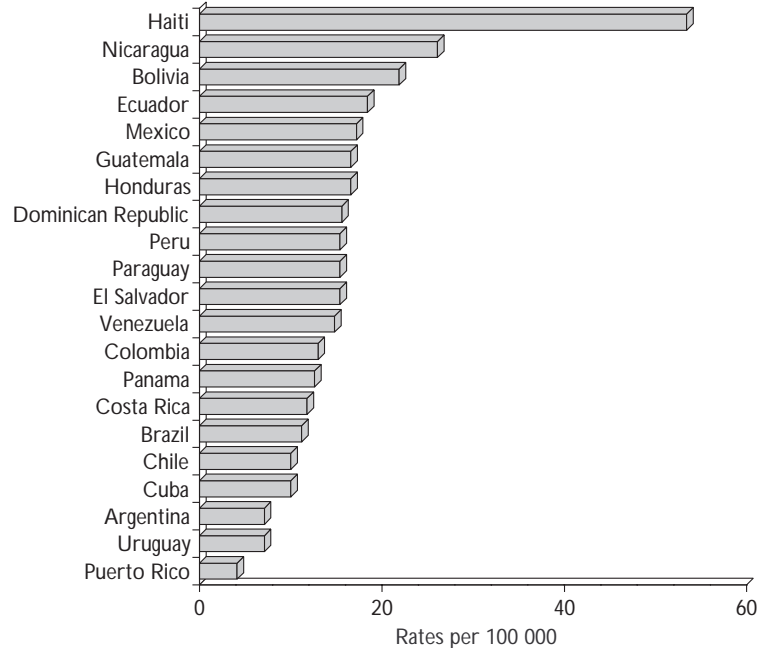

Figure 3. Latin America.Age-Standardized mortality RATE (W ORLD) BY COUNTRIES, 2000

neral the range of variation seems too small to explain differences in the risk of cancer between populations. ${ }^{1}$ Some of the geographical variation may be the result of differences in the prevalence of different subtypes of HPV and host related factors, ${ }^{18,22}$ but the scientific evidence is still too limited to obtain any definitive conclusion.

Geographical variation of other etiological factors may explain some of the variation. High parity, smoking, oral contraception and deficient diets are probably 
Table I

\section{Latin American countries. Estimated cervical CANCER INCIDENCE AND MORTALITY (AGE-STANDARDIZED [WORLD] RATES AND NUMBER OF EVENTS), 2000}

$\begin{array}{cccc} & \text { Incidence } & \text { Mortality } \\ \text { Country } & \text { ASR per } 100000 & \text { Cases } & \text { ASR per } 100000 \text { Deaths }\end{array}$

\begin{tabular}{lrrrr}
$\begin{array}{c}\text { South America } \\
\text { Argentina }\end{array}$ & 14.2 & 2953 & 7.6 & 1585 \\
\hline Bolivia & 58.1 & 1807 & 22.2 & 661 \\
\hline Brazil & 31.3 & 24445 & 11.6 & 8815 \\
\hline Chile & 29.2 & 2321 & 10.6 & 860 \\
\hline Colombia & 32.9 & 5901 & 13.7 & 2339 \\
\hline Ecuador & 44.2 & 2231 & 18.6 & 892 \\
\hline Paraguay & 41.1 & 768 & 15.8 & 281 \\
\hline Peru & 39.9 & 4101 & 15.8 & 1575 \\
\hline Uruguay & 13.8 & 307 & 7.6 & 163 \\
\hline Venezuela & 38.3 & 3904 & 15.2 & 1454
\end{tabular}

Central America

\begin{tabular}{lrrrr} 
Costa Rica & 25.0 & 424 & 12.1 & 197 \\
\hline El Salvador & 40.6 & 1041 & 15.8 & 387 \\
\hline G uatemala & 39.6 & 1432 & 16.8 & 566 \\
\hline Honduras & 39.6 & 833 & 16.8 & 329 \\
\hline Mexico & 40.5 & 16448 & 17.1 & 6650 \\
\hline N icaragua & 61.1 & 997 & 26.1 & 392 \\
\hline Panama & 31.2 & 389 & 13.1 & 158
\end{tabular}

Latin Caribbean

\begin{tabular}{lrrrr} 
Cuba & 23.8 & 1586 & 10.6 & 730 \\
\hline Dominican Republic & 38.4 & 1290 & 15.8 & 495 \\
\hline Haiti & 93.9 & 2428 & 53.5 & 1326 \\
\hline Puerto Rico & 10.3 & 252 & 4.3 & 114
\end{tabular}

co-factors for cervical cancer, increasing the risk among $\mathrm{HPV}$-positive women. ${ }^{23-26}$ Some of these factors are highly influenced by the demographic and socioeconomic patterns of each country. Lower fertility rates and delayed ages at first childbirth are associated with some aspects of socio-economic development (probably female education and literacy). This link between development and cervical cancer has been shown in an ecological analysis of correlates of cervical cancer using data from GLOBOCAN 2000 for all developing countries. ${ }^{27}$ Increased risk of cervical cancer correlates with reduced life expectancy, fewer doctors, more infants with low birth weight and more adults with tuberculosis and HIV, all of which are indicators of low social and economic development. In South America, Argentina and Uruguay, two highly urbanized countries that historically had demographic and developmental patterns similar to those of more developed countries, exhibit risks that are among the lowest in the Region.

Although some of the countries in the region introduced screening programmes several decades ago, it seems unlikely that differences in risks in Latin America can be explained as the result of screening activities. The protective effect of screening in Latin America has been assessed in four case-control studies. ${ }^{28-31}$ All four studies showed a decreased risk for women who had ever received a Pap test but they also pointed out problems related to inadequate coverage and frequency of screening. Another problem faced by screening programmes in Latin America is the inadequate collection and reading of cytological samplings as well as incomplete follow-up of women after the test. ${ }^{32}$

If a screening programme is effective, its impact should be evident through the analysis of time series. Figure 4 shows trends in age-adjusted cervical cancer mortality in eight Latin American countries between 1960 and 1994. It can be seen that in Puerto Rico, with rates similar to those of Mexico, Venezuela and Uruguay at the beginning of the period, there has been a persistent declining trend that placed it, by the end of the 1990s, as the country with the lowest risk in the Region. This decline is concomitant with the introduction of an extended early detection programme, the effect of which can be seen in the progressive decline in age-specific rates, especially in the middle of the age range (30-69) where screening should have the highest effect (Figure 5). A somewhat similar decline can be seen in Cali, Colombia, after the introduction of a screening programme in 1967 (Figure 6), where an increase in registrations of carcinoma in-situ (detected by screening) accompanied the decline in incidence of invasive disease. ${ }^{30}$

In Cuba, Chile, Mexico and Costa Rica, very limited changes in mortality from cervical cancer appear to have followed the introduction of cervical screening. Cervical cancer mortality increased from 1965 onward in Mexico, where a national cervical cancer screening programme was initiated in 1974, and now operates in the Federal District and all 31 states of the country. Although since the 1990s a slightly decreasing trend has been observed, its risk still remains among the highest in the Region. In 1996 the Secretariat of Health in Mexico published a new regulation for the Cervical Cytology Screening Program, changing the frequency of screening, emphasizing the screening of high-risk subjects and giving special consideration to monitoring the quality of cytologic smears. ${ }^{29}$ In Costa Rica, nationwide cytology services have been available to women aged $\geq 15$ years since 1970, but mortality has remained almost unchanged. Improved 


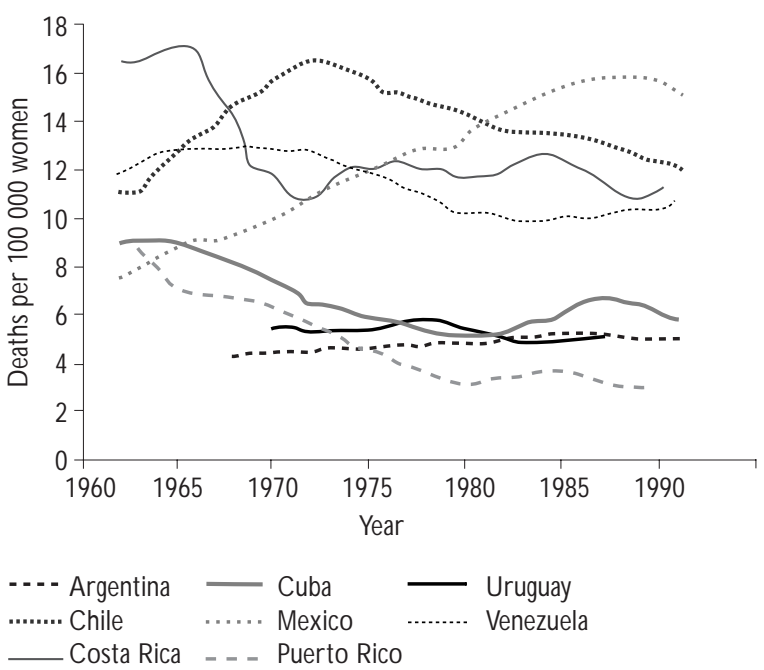

Figure 4. Annual cervical cancer mortality rates (PER 100000 ) in SELECTEd Latin American COUNTRIES, AGE-ADJUSTED TO THE WORLD POPULATION, 1960-1995. FIVE-YEAR MOVING AVERAGES

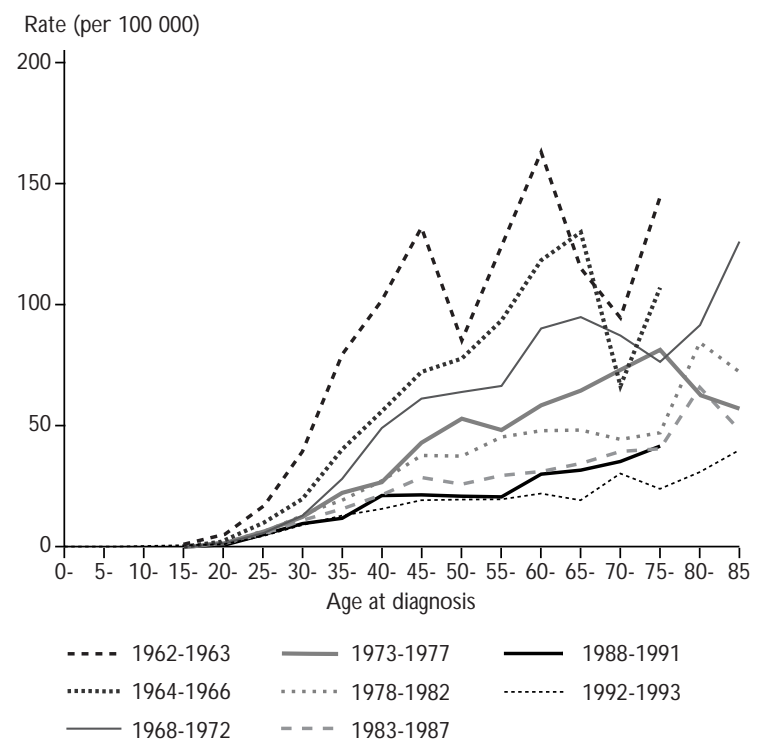

Figure 5. Puerto Rico. Age-specific incidence rates OF CERVICAL CANCER IN SUCCESSIVE TIME PERIODS

reporting and diagnoses have probably masked more pronounced actual declines. ${ }^{3}$ In Cuba, an evaluation of the screening programme was carried out for the pe-

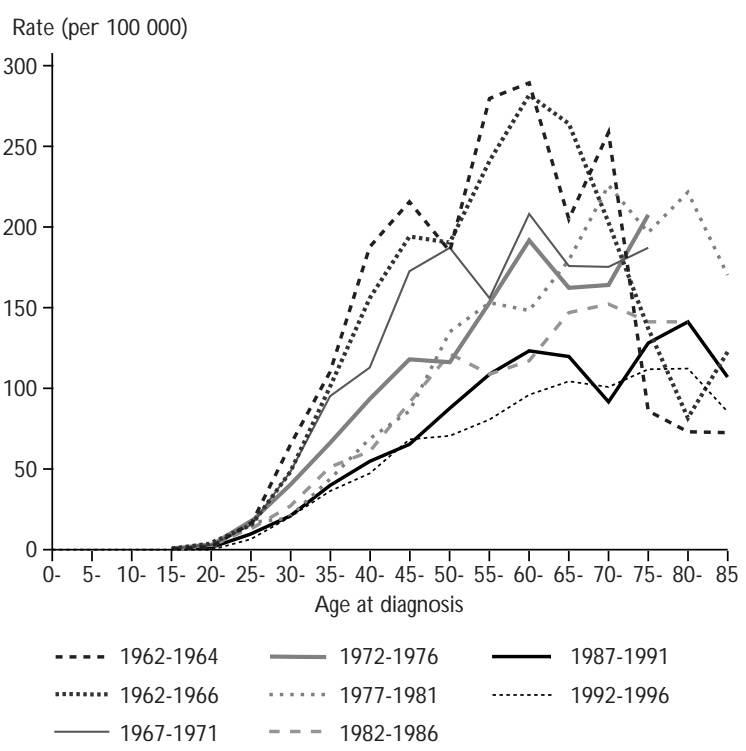

Figure 6. Cali, Colombia. Age-specific incidence RATES OF CERVICAL CANCER IN SUCCESSIVE TIME PERIODS

riod 1980-1994..$^{33}$ According to this evaluation the programme appears to have had no impact on either incidence or mortality.

In Chile, mortality rates increased steadily between 1960 and 1975, and then began to decrease, although at a rather slow pace. This limited decline has been quite disappointing in light of the organized screening programme in practice since the early 1970s. ${ }^{34,35}$ The contrasting evolution of Chile and Argentina is noteworthy, given that these two countries have similar socio-economic and demographic profiles, being in an advanced position in relation to the changes in fertility and mortality patterns which are affecting most Latin American countries. ${ }^{36}$ Contrary to Chile, the mortality rates in Argentina have been, since 1965, among the lowest in the Region, and this in spite of its lack of extended organized screening programmes. In part, this striking difference between the two countries may be more apparent than real, the consequence of differences in coding of uterus cancer deaths. In Chile the proportion of cancer of the uterus reported as "unspecified" has steadily decreased from almost $50 \%$ at the beginning of the 1960 s to around $10 \%$ in the 1990 s. On the contrary, in Argentina, this figure has been of around $45 \%$ for the last 30 years, and the percentage has increased in recent years. ${ }^{37}$ Thus, if rates presented in GLOBOCAN 2000 (corrected for "uterus unspec- 
ified") are considered to compare both countries, the difference between the two countries has been reduced by half (Table I).

\section{The future}

Although population growth in the Region is slowing (from $28 \%$ in $1950-1955$ to an estimated $1.51 \%$ in $1995-$ 2000), there are projected to be quite marked changes in the age structure over the next 20-25 years. Thus, by 2025 the percentage of the population aged 65 and over will double to $10.8 \%$, and in 2050 it will be $20.9 \%$ compared with just $5.6 \%$ today. This will have a marked effect in the burden of chronic diseases, such as cancer, where the risk is highest in the elderly. It is difficult to predict the evolution in the risk of cervix cancer, but as we have seen, although there is some indication of modest declines in some countries, it remains high in most of them. Thus, cervical cancer remains responsible for the death and poor quality of life of thousands of women in age groups with heavy social, economic, and family responsibilities. This has enormous consequences not only for the health status of women but also for the living conditions of their families. All this suffering and deaths are essentially avoidable with existing scientific and technological knowledge. The relative risks for the association between HPV infection and cervical neoplasia are of a magnitude even greater than that for the association between smoking and lung cancer. ${ }^{38}$ However, until effective vaccines for HPV allow realistic primary prevention, early detection and treatment via organized screening programmes remains the strategy of choice. The most cost-effective approaches in different settings have been the subject of increasing debate in recent years, as the reviews in this supplement make clear. But the main challenge remains how to give people access to the available technology to reduce morbidity and mortality from cervical cancer, and for this, a real and urgent commitment from public health officers and decision-makers in the Region is needed.

\section{References}

1. Parkin D M, Bray FI, D evesa SS. Cancer burden in the year 2000. The global picture. Eur J Cancer 2001;37:s4-s66.

2. Restrepo H. Cancer epidemiology and control in women in Latin A merica and the $\mathrm{C}$ aribbean. In: $\mathrm{G}$ ómez E, ed. Gender, women, and health in the Americas. W ashington, D C : PA H O 1993 Scientific Publication: N 0.541. 90-103.

3. Robles SC,W hite F, Peruga A. Trends in cervical cancer mortality in the Americas. Bull Pan Am Health 0 rgan 2002;30:290-3011.
4. Parkin D M. Screening for cervix cancer in developing countries. In: Miller AB, C hamberlain J, D ay N E, Hakama M Prorok PC, ed Cancer screening. C ambridge: UICC, 1991;184-198.

5. Hakama M, Hakulinen T, Pukkala E, Saxen E,Teppo L. Risk indicators of breast and cervical cancer on ecologic and individual levels. Am J Epidemiol 1982;116:990-1000.

6. Hakulinen T, Hansluwka H, López AD, N akada T. G lobal and regional mortality patterns by cause of death in 1980. Int J Epidemiol 1986;15: 226-233.

7. Hakulinen T,Teppo L, Saxen E. Do the predictions for cancer incidence come true? Experience from Finland. Cancer 1986;57:2454-2458. 8. Ferlay J, Bray F, Pisani P, Parkin D M, ed GLO BO CAN 2000: Cancer incidence, mortality and prevalence worldwide. Lyon: IARC Press, 2001; Version 1.0. IARC CancerBase N 0.5.

9. PAHO . Health statistics from the A mericas. W ashington, DC: PAHO, 1998; Scientific Publication N 0.567.

10. Parkin D M, W helan SL, Ferlay J, Raymond L, Young J ed. Cancer incidence in five continents Lyon: IARC, 1997; Scientific Publication No. 143 , Vol VII.

11. World Health O rganization, W HO Mortality Databank. Internet address: http://www-dep.iarc.fr/dataava/infodata.htm.

12. Parkin D M, Pisani P, Ferlay J. Estimates of the worldwide incidence of 25 major cancers in 1990. Int J Cancer 1999;80:827-841.

13. Parkin D M, C hen VW, Ferlay J, Galceran J, Storm H, W helan S. Comparability and quality control in cancer registration. Lyon: IARC, 1994; Technical Report N 0. 19.

14. Mitacek EJ, St Vallieres D, Polednak A P. C ancer in Haiti 1979-84: Distribution of various forms of cancer according to geographical area and sex. Int J C ancer 1986;38:9-16.

15. United N ations. World population prospects:The 2000 Revision. Comprehensive Tables. N ew York (N Y): United N ations, 2001;Vol 1. 16. Parkin D M.The epidemiological basis for evaluating screening policies. In: Franco $\mathrm{E}$, and Monsonego J ed. N ew Developments in cervical cancer screening and prevention. 0 xford: Blackwell Science, 1997;51-69. 17. Bray F, Sankila R, Ferlay J, Parkin D M. Estimates of cancer incidence and mortality in Europe in 1995. Eur J Cancer 2002;38:99-166. 18. Bosch FX, Manos MM, Muñoz N, Sherman M, Jansen AM, Peto J, Schiffman $\mathrm{MH}$ et al. Prevalence of human papillomavirus in cervical cancer: A worldwide perspective. International biological study on cervical cancer (IBSCC) Study Group.J N atl C ancer Inst 1995;87:796-802.

19. Molano M, Posso H,W eiderpass E, van den Brule AJ, Ronderos M, Francheschi S, Meijer $\mathrm{C}$ J et al. Prevalence and determinants of HPV infection among Colombian women with normal cytology. $\mathrm{Br} J \mathrm{C}$ ancer 2002;87:324-333.

20. Lazcano-Ponce E, Herrero R, Muñoz N, Cruz A, Shah KV,Alonso P et al. Epidemiology of HPV infection among Mexican women with normal cervical cytology. Int J C ancer 2001;91:412-420.

21. Herrero R, Hildesheim A, Bratti C, Sherman ME, Hutchinson M, Morales J et al. Population-based study of human papillomavirus infection and cervical neoplasia in rural Costa Rica. J $\mathrm{N}$ atl Cancer Inst 2000; 92:464-474.

22. Bosch FX, de Sanjosé S, Castellsague X, Muñoz N. G eographical and social patterns of cervical cancer incidence. In: Franco E, Monsonego J, ed. $N$ ew developments in cervical cancer screening and prevention. 0 xford: Blackwell Science, 1997;23-33.

23. Muñoz N , Francheschi S, Bosetti C, Moreno V, Herrero R, Smith JS, Shah KV et al. Role of parity and human papillomavirus in cervical cancer:The IARC multicentric case-control study. Lancet 2002;359:1093-1101.

24. Hildesheim A, Herrero R, Castle PE,W acholder S, Bratti MC, Sherman ME et al. HPV co-factors related to the development of cervical cancer: Results from a population-based study in Costa Rica. Br J Cancer 2001;84: 1219-1226. 
25. Moreno V, Bosch FX, Muñoz N, Meijer CJ, Shah KV,W alboomers JM, et al. Effect of oral contraceptives on risk of cervical cancer in women with human papillomavirus infection:The IARC multicentric casecontrol study. Lancet 2002;359:1085-1092.

26. Santos C, Muñoz N , Klug S,A Imonte M, Guerrero I,Alvarez M et al. $\mathrm{HPV}$ types and cofactors causing cervical cancer in Peru. $\mathrm{Br} J \mathrm{C}$ ancer 2001;85:966-971

27. D rain PK, Holmes KK, Hughes JP, Koutsky LA. D eterminants of cervical cancer rates in developing countries. Int J Cancer 2002;100:199-205

28. Hernández-Avila M, Lazcano-Ponce EC, de Ruiz PA, Romieu I. Evaluation of the cervical cancer screening programme in Mexico:A population-based case-control study. Int J Epidemiol 1998;27:370-376. 29. Jiménez-Pérez $M$,Thomas $D B$. Has the use of pap smears reduced the risk of invasive cervical cancer in Guadalajara, Mexico? Int J Cancer 1999; 82:804-809

30. Aristizabal N, C uello C, Correa P, C ollazos T, H aenszel W. The impact of vaginal cytology on cervical cancer risks in C ali, C olombia. Int J Cancer 1984;34:5-9.

31. Herrero R, Brinton LA, Reeves W C, Brenes MM, de Britton RC, $G$ aitan $E$ et al. Screening for cervical cancer in Latin A merica: $A$ case-control study. Int J Epidemiol 1992;21:1050-1056.
32. Lazcano-Ponce EC, Alonso de Ruiz P, López-C arrillo L, N ájeraA guilar $\mathrm{P}$,Avila-C eniceros R, Escandón-Romero $\mathrm{C}$ et al.Validity and reproducibility of cytologic diagnosis in a sample of cervical cancer screening centers in Mexico.Acta Cytol 1997 Mar-A pr;41(2):277-284. 33. Pan American Health 0 rganization. Evaluation of the cervical cancer control program in Cuba (Short Communication). Bull Pan Am Health O rgan 1996:30:387-391.

34. Taucher E,Albala C, Icaza G. Adult Mortality from chronic diseases in C hile, 1986-90. In:Timaeus I, C hackiel J, Ruzicka L, ed.A dult mortality in Latin America. 0 xford: Clarendon Press, 1996:253-275.

35. Sankaranarayanan R, Budukh AM, Rajkumar R. Effective screening programmes for cervical cancer in low- and middle-income developing countries. Bull W orld Health O rgan 2001;79:954-962.

36. Frenk J, Bobadilla SL, Lozano R. The epidemiological transition in Latin A merica. In:T imaeus I, C hackiel J, Ruzicka L, ed. Adult mortality in Latin America. 0 xford: Clarendon Press, 1996:123-139.

37. Argentina, Ministry of Health. Estadísticas vitales. Información básica año 2000. Buenos Aires: Dirección de Estadísticas e Información de Salud, 2000 .

38. Franco E, D uarte-Franco E, Ferenczy A. Cervical cancer: Epidemiology, prevention and the role of human papillomavirus infection. CMAJ 2001; 164(7):1017-1025. 